ojs.uv.es/index.php/qdfed

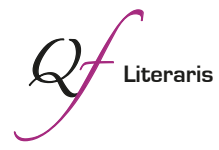

Per a citar aquest article: Ros, Violeta; Rosón, María \& Valls, Lurdes. 202I. "Contrafiguras de la violencia. Imágenes, relatos y arquetipos de la perpetración de los crímenes del franquismo”. Quaderns de

Filologia: Estudis Literaris XXVI: 9-I9.

doi: $10.7203 /$ qdfed.26.22095

\title{
Contrafiguras de la violencia. Imágenes, relatos y arquetipos de la perpetración de los crímenes del franquismo
}

Counterfigures of violence. Images, narratives and archetypes of the perpetration of the crimes of Franco's regime.

Violeta Ros

Universitat de València violeta.ros@uv.es

MARÍA Rosón

Universidad Complutense de Madrid mroson@ucm.es

LURDES VALLS

Universitat de València

lurdes.valls@uv.es

\section{La cuestión de la perpetración en los estudios sobre el franquismo}

La cuestión de la perpetración -lo que en el mundo anglosajón se conoce como perpetrator studies- constituye uno de los últimos giros en los estudios de la violencia política, su memoria y sus representaciones. Lo que implica esta propuesta es, en realidad, un giro en el foco de la reflexión sobre los procesos de representación y memorialización de la violencia política; el giro hacia una categoría de análisis no siempre transparente: la categoría del perpetrador. Más allá de su especificidad como significante dentro del léxico jurídico, la noción de la perpetración presenta un gran potencial analítico en términos de crítica cultural. Desde una acepción amplia, el perpetrador deviene la contrafigura de la víctima; una contrafigura más o menos genérica que adquiere significados concretos y específicos en función de los diversos contextos históricos y sociales en los que se inserta, y en función también de 
las necesidades, los marcos y los límites del discurso del presente desde el que se articula todo proceso de memoria ${ }^{\mathrm{T}}$.

Precisamente por su carácter complejo, poco transparente y, en ciertos contextos, de límites escurridizos, la propia noción de perpetrador opera como una categoría disponible a la hora de analizar la memoria de los procesos de violencia política y sus representaciones culturales. La reflexión en torno a la perpetración nos permite, por tanto, pensar más allá de la figura individual del victimario y del verdugo, es decir, del agente individual de la violencia. Nos permite comprender los procesos de violencia política ocurridos en el pasado como entramados sociales de gran alcance y duración en el tiempo y que presentan, además, efectos políticos y simbólicos que perduran todavía en el presente, muy especialmente a través de ciertos relatos sociales y representaciones culturales. Es así como el análisis crítico y meticuloso de estos relatos e imágenes que giran en torno a las contrafiguras de la violencia política alumbra un campo de investigación sugerente y todavía poco explorado al que los artículos reunidos en este monográfico, sin duda, tienen mucho que aportar.

A la volatilidad que, en el campo conceptual, presenta la noción del perpetrador de violencia política se le suman las dificultades añadidas de cada contexto específico, provocadas por las distintas configuraciones de los marcos del discurso sobre la perpetración y sobre la violencia política que lo conforman. En este sentido, influyen de forma decisiva los límites de lo decible y lo pensable en relación con esos episodios de violencia política que cada contexto temporal y geográfico pone en juego. Desde esta perspectiva, este monográfico es una invitación a la reflexión interdisciplinar en torno a la iconografía del perpetrador y a la memorialización de la perpetración en el contexto de la violencia política del franquismo, atendiendo a sus particularidades específicas.

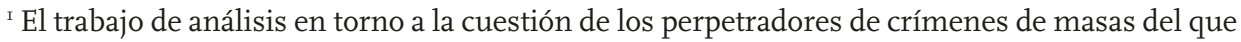
forma parte este monográfico ha sido desarrollado por el grupo de investigación REPERCRI, dirigido por Vicente Sánchez-Biosca, Anacleto Ferrer, Brigittte Jirku. El fruto del trabajo conjunto de las investigaciones llevadas a cabo por este equipo en torno a la cuestión de los perpetradores puede consultarse, entre otras publicaciones, en los volúmenes titulados El infierno de los perpetradores. Imágenes, relatos y conceptos (Ferrer \& Sánchez-Biosca, 2019) y Geographies of Perpetration. Re-Signifying Cultural Narratives of Mass Violencie (Jirku \& Sánchez-Biosca, 202I).
} 


\section{Rocío y los marcos de sentido del Estado democrático}

A causa de su prolongación en el tiempo y a causa también de las características del proceso transicional que la siguió, el caso de la dictadura franquista presenta una especial dificultad, no solo a la hora de pensar los procesos de memoria desde la noción de los perpetradores, sino también a la hora de identificarlos y nombrarlos como tales. Como muestra de la dificultad y de los problemas que conlleva el hecho de nombrar al perpetrador en nuestro contexto, recordemos lo ocurrido con el documental Rocío, que pasó a la historia como uno de los casos más paradigmáticos de censura cinematográfica producida ya durante el periodo democrático, al ser secuestrada judicialmente por el Estado español, una vez derogada la censura cinematográfica en I977. Dirigido y producido por Fernando Ruiz Vergara y por Ana Vila, el documental fue estrenado en I981, tras un largo y difícil proceso de distribución (Alvarado, 20I3). La pieza tuvo una vida social atormentada precisamente porque, de forma muy temprana, abordó la cuestión de la perpetración de los crímenes del franquismo en clave de denuncia.

Si hay algo que transmite Rocío es que el pasado no está cerrado y que sus estructuras de violencia continúan reverberando en nuestro presente. Del mismo modo que nos muestra cómo en las romerías continúa destacando el "caballero" privilegiado como sucedía en tiempos feudales, reproduciendo un rito que reafirma los valores aristocratizantes de los grandes ganaderos y su poder económico, político y social, la película encarna, en su propia historia de producción y recepción, el castigo que supone nombrar y desvelar la trama de violencia producida por esos mismos poderes fácticos, que también fueron los del franquismo. Noventa y nueve hombres y una mujer fueron asesinados durante 1936 en Almonte, provincia de Huelva, por una banda de falangistas con camisa azul y la medalla de la virgen del Rocío, encabezada, presuntamente y según declara uno de los vecinos entrevistados para el film -y según estuvieron dispuestos a ratificar después muchos otros vecinos durante el proceso judicial del que dicho film fue objeto ${ }^{2}$ - por el terrateniente y devoto de la virgen del Rocío, José M. ${ }^{a}$ Reales Carrasco. El 23 de febrero de I98I, el mismo día en el que Tejero protagonizaba el intento de golpe de Estado en el

\footnotetext{
${ }^{2}$ Durante el juicio, más de una decena de ancianos de Almonte se presentaron ante el juez, dispuestos a testificar la veracidad del testimonio de Pedro Gómez Clavijo, en relación con la perpetración de los crímenes cometidos en su pueblo durante la guerra. Su testimonio, reproducido en la película, fue desestimado por el juez.
} 
Congreso, sus hijos interpusieron una querella en la Audiencia Provincial de Sevilla contra los responsables del documental. Aducían que la película incurría en injurias graves contra la memoria de su padre y que suponía, además, un escarnio y un ultraje público a la fe católica y a misma Romería del Rocío (Mateo, 20I7: I67). La denuncia incluía, además, a Pedro Gómez Clavijo, el vecino de Almonte que cuenta ante la cámara los episodios de represión ocurridos en su pueblo y señala con nombres y apellidos al ideólogo y uno de los perpetradores de la represión en Almonte durante la Guerra Civil: José M. ${ }^{a}$ Reales Carrasco 3 .

Tras declararse como único responsable del documental para evitar las penas sobre los demás enjuiciados, Fernando Ruiz Vergara fue condenado por un delito de injurias graves contra José María Reales Carrasco. Además, se prohibió la distribución de la película hasta que no se eliminase de ella todo rastro que relacionase a este último con la represión durante la guerra (Mateo, 2017: I68-I69). La secuencia del testimonio de Pedro Gómez Clavijo fue sustituida entonces por una sucesión de fotogramas en los que se podía leer: "Estas imágenes no pueden ser vistas ni oídas por Sentencia de I9/06/1982 de la Causa I48/8 de la Sala Segunda del Tribunal Provincial de Sevilla. Ratificada por Sentencia de 3/4/1984 de la Sala Segunda del Tribunal Supremo"4. Años después, esta secuencia también fue eliminada en su emisión en RTVE, sin el consentimiento del autor (Del Río Sánchez \& Espinosa Maestre, 2013: 87). De este modo, ya en pleno periodo democrático, no solamente se censura el acto de nombrar e identificar al perpetrador de los crímenes del franquismo, sino que también se borra la propia huella de la censura judicial en relación con ese acto de nombrar, de desvelar al responsable directo de la muerte de cien personas, haciendo transparentes, de forma involuntaria, los límites del discurso público sobre la perpetración de los crímenes de la Guerra Civil y el franquismo.

\footnotetext{
3 Para más información sobre la vida pública y el devenir de los implicados en el documental Rocío puede consultarse tanto el capítulo "Espectros que emergen: imágenes de la guerra en la transición española" de la tesis doctoral Imágenes clandestinas y saber histórico. Una genealogía del cine clandestino del Tardofranquismo y la Transición (Mateo Leivas, 20I7), así como la obra colectiva El caso Rocío. La historia de una película secuestrada por la transición (Del Río Sánchez, Espinosa Maestre y Sánchez, 2013).

${ }^{4}$ Esta secuencia se puede ver completa en el documental El caso Rocío. La historia de una película secuestrada por la transición, dirigido por José Luis Tirado en 2013. El documental se puede ver completo en el siguiente enlace: https://www.joseluistirado.es/p-e-1-\%C3\%AD-c-u-l-a-s/ el-caso-roc\% $3 \%$ ADo/
} 


\section{El espectro de los perpetradores}

Es importante recordar la lectura en perspectiva de la tumultuosa vida social que tuvo la película de Fernando Ruiz Vergara porque hace evidente que, después de la Transición, en el Estado español ciertas estructuras de poder vinculadas al franquismo y los marcos normativos que se derivan de ellas han seguido vigentes, de forma más o menos velada, permeando la etapa democrática. Nombrar, invocar la perpetración de los crímenes del franquismo -y, con ello, también a los perpetradores y a sus víctimas-, señalar al poderoso y desafiar su impunidad es, precisamente, lo que la película Rocío pone en escena. Y lo hace, en definitiva, como un ejercicio de reparación que, ya en el contexto democrático, es doblemente censurado. De este modo, a principios de los años ochenta la propia película sufre a través de la censura el castigo del mismo poder que describe y denuncia.

En un trabajo del año 2000, Joan Ramón Resina escribía sobre la necesidad de desarrollar una "teoría crítica de los fantasmas" entendida como una propuesta teórica que elaborara una aproximación a las políticas de la memoria desplegadas durante y después de la transición de la dictadura a la democracia en España (Resina, 2000: I3). Según Resina, estas políticas de la memoria se caracterizaron no solo por "lo mucho que se ha olvidado intencionalmente", sino también por "lo mucho que se está convirtiendo en cada vez más difícil de recordar” (Resina, 2000: I3). Tanto el propio Resina como Jo Labanyi en un texto publicado en ese mismo volumen (Labanyi, 2000) proponen y adaptan el concepto de "hauntología" que Jacques Derrida desarrolló en su ya mítico trabajo Espectros de Marx para nombrar esos fantasmas. Frente a la ontología, que encierra la pregunta por el ser, Derrida propone la "hauntología" como un acercamiento que desplaza este ser-ente a un estado espectral: "aquello que no está ni vivo ni muerto, ni presente ni ausente" (Derrida, 20I2: 64). El pasado se convierte, de este modo, en "un espacio virtual de la espectralidad" (Derrida, 20I2: 25) que cuestiona el sentido lineal de la historia, ya que entiende el tiempo histórico como una secuencia que está fuera de quicio, descoyuntada (out of joint). Desde esta lógica temporal desquiciada, en esta hauntología entendida como teoría política, la figura del fantasma debe ser convocada para otorgarle un lugar en el presente y, de este modo, también el derecho a la memoria y a la reparación. Tal y como señala el propio Derrida, "ese ser-con los espectros sería también -no solamente, pero también- una política de la memoria, de la herencia y de las generaciones" (Derrida, 20I2: I2). 
Desde esta teoría política de los fantasmas que proponen autores como Resina, Labanyi y Colmeiro (20II) o Thomas (20I9), entre otros, y partiendo de la definición que estos autores proponen de lo fantasmagórico en su acepción memorial, cabría preguntarse, entonces, quiénes son esos fantasmas. Si atendemos estrictamente a lo que estos autores proponen, lo hauntológico tendría que ver solamente con la forma de hacerse presente que tienen los parias, los olvidados, las víctimas de la historia: es decir, los trazos de aquellos a quienes no se les ha permitido dejar trazo, que se manifiestan como latencias en el presente para exigir reparación y justicia. Sin embargo, puesto que lo que esta teoría política de los fantasmas pone en juego es, en definitiva, el retorno de lo reprimido en la historia, los espectros de la perpetración pueden ser igualmente convocados, para ser nombrados y señalados en el presente.

En principio, las figuras de la perpetración de los crímenes del franquismo -ideólogos, ejecucionarios, verdugos, cómplices- no caerían dentro de la categoría de lo hauntológico en la forma como esta se ha presentado y tratado en los estudios sobre la posmemoria. Y no lo hacen principalmente porque la categoría del fantasma se codifica, en este tipo de aproximaciones, a partir de la experiencia del trauma histórico y de la idea de su repetición; una repetición que se manifiesta, además, en la herencia y la transmisión que ese trauma va operando en las generaciones sucesivas. Esta aproximación se relaciona, por tanto, únicamente con las víctimas de la historia y, especialmente, de los fascismos que asolaron la Europa del siglo xx.

Evidentemente, es imposible concebir a quienes perpetraron los crímenes que hay tras esta herencia traumática como víctimas silenciadas: en su experiencia no hay trauma producido por el olvido intencional de la injusticia sufrida. Los perpetradores no son fantasmas porque siguen entre nosotros: pero no lo hacen en calidad de perpetradores puesto que su identidad en tanto que perpetradores ha sido, en este sentido, borrada -blanqueada, incluso-. Sin embargo, la pregunta por el carácter espectral de los perpetradores en el contexto del franquismo nos parece aquí pertinente porque apunta directamente hacia las condiciones de posibilidad que precedieron y vertebraron sus vidas y las de sus descendientes, en las que no operó un proceso de olvido, pero sí un proceso de obliteración parcial: un mecanismo de olvido intencional, de olvido buscado, calculado y trabajado.

Si observamos desde el presente, lo que ocurre con estas figuras de la perpetración es un proceso de escisión: una suerte de disociación pública donde la Historia y el recuerdo no los borra a ellos, sino que borra de ellos, precisamente, los signos y las marcas que los identifican como perpetradores. De 
este modo, la responsabilidad sobre los actos de violencia que suponen, entre otras cosas, la causa sui del mantenimiento o mejora de su posición socioeconómica, se escinden de ellos mismos a través de una transformación pública donde su yo se desdobla, se bifurca en un proceso en el que lo que resulta espectral no son ellos mismos, sino su faceta de perpetradores de crímenes de guerra y la condición de causa primaria que ese tomar partido por el bando sublevado tuvo en relación con los beneficios posteriores que obtuvieron. Y esto es, precisamente, lo que ocurre con la vida social del documental Rocío: la pieza enfrenta al hombre notable, al terrateniente devoto de la virgen del Rocío, con su fantasma, y lo enfrenta a su doble siniestro perpetrador. En definitiva, la película vuelve a unir lo que había quedado escindido por ese proceso de obliteración social intencional.

De este modo, si bien es cierto que los perpetradores no pueden entenderse en un sentido estricto como los fantasmas que Derrida anima a desvelar, sí que podemos entender que la perpetración que llevaron a cabo y que queda escindida y velada ocupando el lugar del doble siniestro, forma parte del universo fantasmagórico que viene del pasado e invade, con su fantasmal trazo, nuestro presente. Y esto sucede porque se traza una dialéctica de necesidad recíproca entre la negación de los fantasmas en tanto que víctimas y la negación de la perpetración que los hizo devenir espectros. De este modo, exorcizando a los fantasmas de las víctimas, llegamos como una consecuencia lógica a desvelar y confrontar la siniestra contrafigura de sus perpetradores.

\section{El giro de los perpetradores en las representaciones culturales contemporáneas}

El monográfico “Contrafiguras de la violencia. Imágenes, relatos y arquetipos de la perpetración de los crímenes del franquismo" parte de la constatación de la dificultad que existe, en el contexto español, a la hora de nombrar a quienes ejercieron, de distintas maneras, en diferentes periodos y con distintos grados de implicación y de conciencia, la violencia política, primero a favor del bando sublevado durante la guerra y después, en nombre o a favor del Estado durante la dictadura franquista. Esta dificultad radica en parte en el papel que, por acción u omisión, han jugado los procesos judiciales de los crímenes del franquismo en España. En la mayor parte de los casos, el hecho de que estos procesos no hayan tenido lugar ha entorpecido, en mayor medida que en otros contextos, la capacidad de pensar, nombrar y, por tanto, imaginar las 
figuraciones concretas de quienes perpetraron la represión franquista en sus múltiples facetas.

En las páginas que siguen el lector encontrará una serie de trabajos que indagan en una serie de modelos o arquetipos que tratan de localizar las diferentes figuras del perpetrador fundamentalmente a partir de sus representaciones culturales, puesto que es en ellas donde se ha intentado hacer presente lo ausente: donde se ha intentado exorcizar a los fantasmas de las víctimas, por un lado, y a los dobles siniestros de los perpetradores, por otro.

El proceso político y cultural que se inicia en España con el cuestionamiento de los pactos de la Transición y con la progresiva renovación del lenguaje utilizado para nombrar los episodios de violencia política derivados del golpe de 1936 y que se prolongaron hasta más allá de la década de los setenta, ha entrado en diálogo, en los últimos años, con un marco global de comprensión de los procesos de memoria de la violencia política entendidos como experiencias traumáticas colectivas. Sin duda, el desplazamiento del foco de atención desde el conflicto -Golpe de Estado de I936, Guerra Civil y Dictadura- hacia el posconflicto -tardofranquismo y Transición-ocurrido en los últimos años en el caso español, ha permitido conectar los procesos de memoria histórica en España con las demandas de justicia transicional dentro de los marcos transnacionales de memoria. En este escenario, el recurso al lenguaje de los derechos humanos -en concreto, a las categorías viajeras como desaparecido (Ferrándiz, 20I0) o incluso la propia categoría de los perpetradores-se convierte en una sugerente herramienta de análisis cultural, puesto que, en la práctica social, estos tecnicismos legales tienen el enorme potencial de producir nuevas subjetividades, nuevas relaciones y, sobre todo, nuevos vínculos con el pasado reciente que trascienden el ámbito meramente judicial y que se ven reflejados también en la articulación de nuevos relatos culturales.

Durante los últimos años hemos asistido, en consecuencia, a la aparición y consolidación de una nueva sensibilidad y un nuevo lenguaje para nombrar los efectos de la Guerra Civil, el franquismo y la Transición? con un lenguaje global, que también permeará a la producción cultural, especialmente a la cinematográfica y literaria. Películas como La isla mínima (Alberto Rodríguez, 2014) o El sustituto (Óscar Aibar, 202I); documentales como La causa contra Franco (Dietmar Post \& Lucía Palacios, 20ı8), Lesa Humanidad (Héctor Faver, 20I7) o Billy. Torturas, impunidad, silencio (Max Lemcke, 2020) y novelas como Honrarás a tu padre y a tu madre (Fallarás, 2018), Dicen (Arins, 20I9) o pequeñas mujeres rojas (Sanz, 2020) abordan la representación de los crímenes del franquismo desde la indagación en la impunidad de los perpetradores, 
entendida como un asunto pendiente; como la gran deuda con el pasado sin la que cualquier tipo de reparación resulta difícil, si no imposible. De este modo, la cuestión de la impunidad de los crímenes del franquismo, de la revisión crítica del proceso transicional en general y de la aplicación de la Ley de Amnistía, en particular, traen a escena, de forma inevitable, la cuestión de los perpetradores y, ponen el foco sobre esta problemática de forma directa.

De todo ello dan cuenta los ocho trabajos que componen este número monográfico. Los dos primeros artículos, firmados por Javier Sánchez Zapatero y María Ángeles Naval abordan la circulación de la figura del perpetrador en las narrativas del presente. Si bien en su trabajo "Víctimas y victimarios en la literatura española de la memoria, de la Guerra Civil a la actualidad: el caso de Dicen, de Susana Sánchez Arins", Sánchez Zapatero presenta una lectura de la novela Dicen (Sánchez Arins, 20I9) en contraste con el proceso de difuminación de la figura del perpetrador en la literatura española de los siglos xx y xxi, en el trabajo titulado "Estirpe de perpetradores (pequeñas mujeres rojas de Marta Sanz, novela negra de la memoria histórica)”, María Ángeles Naval explora la pervivencia de la herencia y la culpa de los perpetradores y delatores en el presente a partir de pequeñas mujeres rojas (Sanz, 2020). En su análisis de la novela de Marta Sanz, Naval se centra en la condición codiciosa y criminal de muchos de los crímenes políticos perpetrados durante la Guerra Civil y el franquismo, subrayando de este modo el móvil económico de dichos crímenes. En esta misma línea, en el texto "Los grandes estraperlistas. Imágenes, deformaciones y silencios en la propaganda, cine y novela de la posguerra franquista”, Miguel Ángel del Arco indaga en la corrupción económica del franquismo a partir de las representaciones del estraperlo promovidas por el Régimen en sus medios afines, por contraste a los que encontramos en algunas de las novelas y películas más icónicas de la época, como la novela Nada (Laforet, I945) o la película Surcos (Nieves Conde, I95I), entre otras. El trabajo de Clara Gutiérrez, titulado "Perpetradores franquistas: teorías, discursos y prácticas. Un análisis desde la perspectiva de género" indaga en la dimensión de género en el análisis de la perpetración durante la guerra y la más inmediata posguerra, trabajando con el archivo de los discursos radiofónicos de Queipo de Llano en intersección con las teorías del psiquiatra Vallejo Nájera y los testimonios de las mujeres que durante el tardofranquismo fueron torturadas por la policía de la Brigada Político Social. Estos tres casos de estudio, aparentemente dispares, ofrecen en su análisis relacional la constatación de los componentes estructuralmente patriarcales de la violencia franquista. 
De una forma directa y desde una perspectiva historiográfica, los trabajos de José Luis Rodríguez, Ana Álvarez y Miriam Saqqa se ocupan de analizar la figura de los perpetradores en diferentes contextos. Si bien en su trabajo titulado "Perpetradores de violencia. El arquetipo de funcionario de la policía política y propagandista de la teoría de la conspiración antiespañola: Mauricio Carlavilla y Eduardo Comín Colomer", Rodríguez se ocupa de diseccionar la evolución de la figura del policía propagandista a partir de dos estudios de caso y Miriam Saqqa, en su texto "El perpetrador y su construcción como 'víctima'. Los 'Mártires y Caídos por Dios y por España”, aborda la operación discursiva por la cual el franquismo logró formular a los perpetradores de los crímenes de guerra por parte del bando nacional en víctimas del terror y mártires de la patria, Ana Álvarez se adentra, en su trabajo “¿Víctimas o verdugos? El perfil de los perpetradores en La paloma de Ravensbrück”, en el análisis de la representación literaria de los perpetradores en los campos de concentración nazis a partir de la lectura de La paloma de Ravensbrük (Martí, 20I2) desde la clave biopolítica.

A modo de cierre del monográfico, los trabajos "El perpetrador en su laberinto. Un análisis comparado de cómo los perpetradores habitan los espacios de memoria" y “¿Qué hacen los perpetradores cuando hablan? Aportes metodológicos a partir de una investigación sobre declaraciones públicas de represores (Argentina, I976-20I8)", de Antonio Míguez y Claudia Feld y Valentina Salvi respectivamente, aportan una lúcida visión de conjunto y en perspectiva de los modos en que los perpetradores se hacen presentes en el espacio público en el contexto global.

\section{Bibliografía}

Alvarado, Alejandro. 20I3. Un lobo con piel de cordero. La censura en el cine documental después de Franco. En Del Río Sánchez, Ángel; Espinosa Maestre, Francisco \& Sánchez, Pura (coord.) El caso Rocío. La historia de una película secuestrada por la transición. Sevilla: Aconcagua Libros, 67-78.

Colmeiro, José. 20II. A Nation of Ghosts? Haunting, Historical Memory and Forgetting in Post-Franco Spain. $45^{\circ}$ F. Electronic Journal of Theory of Literature and Comparative Literature 4: I7-34.

Derrida, Jacques. 20I2. Espectros de Marx. El estado de la deuda, el trabajo del duelo y la nueva internacional. Madrid: Trotta.

Del Río Sánchez, Ángel \& Espinosa Maestre, Francisco. 20I3. El "caso Rocío" y la transición. Persecución, hostigamiento y caída de Fernando Ruiz Vergara. En Del Río Sánchez, Ángel; Espinosa Maestre, Francisco \& Sánchez, Pura (coord.) 
El caso Rocío. La historia de una película secuestrada por la transición. Sevilla: Aconcagua Libros.

Del Río Sánchez, A. (s. f.). Otras víctimas de la transición. Persecución, secuestro y censura del filme Rocío de Fernando Ruiz Vergara. Todos los nombres. https://todoslosnombres.org/sites/default/files/documento338_o.pdf [Acceso Io/IO/202I]

Ferrándiz, Francisco. 2010. De las fosas comunes a los derechos humanos. El descubrimiento de las desapariciones forzadas en la España contemporánea. Revista de Antropología Social I9: I6I-I89.

Ferrer, Anacleto \& Sánchez-Biosca, Vicente. 20I9. El infierno de los perpetradores. Imágenes, relatos y conceptos. València: Alfons el Magnànim/Edicions Bellaterra.

Jirku, Brigitte E. \& Sánchez-Biosca, Vicente. 2021. Geographies of Perpetration. Re-Signifying Cultural Narratives of Mass Violence. Peter Lang.

Labanyi, Jo. 2000. History and Hauntology; or What Does One Do with the Ghosts of the Past? Reflections on the Spanish Film and Fiction of the Post-Franco Period. En Ramon Resina, Joan (ed.) Disremembering the Dictatorship: The Politics of Memory since the Spanish Transition to Democracy. Ámsterdam: Rodopi, 65-82.

Mateo Leivas, Lidia. 20I7. Espectros que emergen: Imágenes de la guerra en la Transición española. En Imágenes clandestinas y saber histórico. Una genealogía del cine clandestino del Tardofranquismo y la Transición (Tesis Doctoral). Madrid: UAM, I65-I70.

Resina, Joan Ramón. 2000. Introduction. En Ramon Resina, Joan (ed.) Disremembering the Dictatorship: The Politics of Memory since the Spanish Transition to Democracy. Ámsterdam: Rodopi, I-I6.

Thomas, Sarah. 2019. Inhabiting the In-Between. Childhood and Cinema in Spain's Long Transition. Toronto: University of Toronto Press. 
